\title{
Arabidopsis RAV1 is down-regulated by brassinosteroid and may act as a negative regulator during plant development
}

\author{
Yu Xin HU*, Yong Hong WANG*, Xin Fang LIU, Jia Yang LI $^{* *}$ \\ Institute of Genetics and Developmental Biology, Chinese Academy of Sciences, Beijing 100101, China.
}

\begin{abstract}
RAV1 is a novel DNA-binding protein with two distinct DNA-binding domains unique in higher plants, but its role in plant growth and development remains unknown. Using cDNA array, we found that transcription of RAV1 is downregulated by epibrassinolide (epiBL) in Arabidopsis suspension cells. RNA gel blot analysis revealed that epiBL-regulated $R A V 1$ transcription involves neither protein phosphorylation/dephosphorylation nor newly synthesized protein, and does not require the functional BRI1, suggesting that this regulation might be through a new BR signaling pathway. Overexpressing RAV1 in Arabidopsis results in a retardation of lateral root and rosette leaf development, and the underexpression causes an earlier flowering phenotype, implying that RAV1 may function as a negative regulatory component of growth and development.
\end{abstract}

Keywords: RAV1, Brassinosteroid, signal transduction, Arabidopsis thaliana.

\section{INTRODUCTION}

Brassinosteroids (BRs) are natural plant growth-promoting products, which have structures similar to animal steroid hormones and are distributed throughout the plant kingdom[1]. Exogenous application of BR at nanomolar to micromolar levels causes a number of physiological responses. BR-deficient and -insensitive mutants exhibit severe alterations in plant growth and development, such as de-etiolation, dramatic dwarfism, reduced fertility, and extended longevity[2]. In addition to a role in plant growth and development, BR has been also implicated in the modulation of plant stress responses, including enhancement of chilling-, thermo-, salt-tolerance and protection of plant from the mild drought injury and pathogen attack[2]. Till now, at least eight genes have been confirmed to lead to the BR biosynthetic deficiency[3]. The characterization of these mutants leads not only to the confirmation of its essential role in plant growth and development as a new class of plant hormone, but also to the elucidation of BR biosynthetic pathway[4].

The first invaluable insight regarding the BR signal transduction comes from the identification and characterization of a BR-insensitive mutant, bri1 [5, 6]. BRI1 is a membrane-located receptor kinase and recent works have confirmed its critical role in perceiving and transducing BR signal as a membrane-located receptor[7, 8]. Great ad-

\footnotetext{
"These authors contributed equally to this work.

${ }^{* *}$ Correspondence author: Jia Yang LI

Tel: 0086-10-64852855, Fax: 0086-10-64873428,

E-mail: jyli@genetics.ac.cn
}

vances have been achieved recently by the identification and characterization of other signal molecules involved in this pathway, including BSR1, BIN2, and BAK1[9-13]. On the other hand, some works focus on the BR-regulated genes in attempting to elucidate the molecular mechanism of BR-mediated development. The early observations that BR regulates the expression of $B R U 1$ in soybean[14] and TCH4 in Arabidopsis [15] provide molecular evidences that $\mathrm{BR}$ is involved in regulation of cell elongation and expansion. Our primary result that BR induces $C y c D 3$ transcription in Arabidopsis represents the finding of BR-regulated cell division[16]. BR also mediates light-dependent development[17] and their signals are integrated via a darkinduced $\mathrm{G}$ protein[18]. Some other BR-regulated genes and signaling components have been characterized recently, including Cdc2b, KOR and BAS1[19-21]. Furthermore, a number of BR response genes have been identified using DNA array approach[22-24]. The characterization of these genes will greatly further our understanding of molecular mechanism of BR action and signal transduction.

RAV1 is a putative DNA binding protein with two distinct types of DNA binding domains, AP2 and VP1/B3[25]. AP2 domain was first identified as a DNA binding domain in a family of tobacco ethylene response element binding proteins (EREBPs)[26] and in Arabidopsis APETALA2 (AP2), a transcriptional factor involved in flower development[27]. The number of different proteins containing the AP2 domain appears to be quite large in plants[28, 29]. Some of them, such as Arabidopsis ANT, TINY and CBF1, 
have been shown to be involved in flower development, cell proliferation, and plant responses to hormones and stresses[27, 30, 31]. VP1/B3 is another DNA binding domain conserved in a number of DNA binding proteins, such as VP1, ABI3 and ARF1, which have been shown to mediate the plant responses to ABA and auxin [32-34]. RAV1 containing both AP2 and VP1/B3 domains suggests that it represents a new group of DNA binding proteins unique to higher plants. However, little is known about its role in plant growth and development[25].

By a cDNA array, we screened for BR response genes in Arabidopsis det 2 cell culture and 53 clones were identified to be responsive to epibrassinolide (epiBL) treatment, including $C y c D 3$ and $R A V 1$ [22]. Here we report that the transcription of $R A V 1$ is down-regulated by epiBL treatment and this regulation of $R A V 1$ by epiBL seems not to require the functional BRI1. Overexpression and underexpression of RAV1 in Arabidopsis result in a retardation of lateral root and rosette leaf development and earlier flowering, respectively. Our results suggest that RAV1 may act as a negative growth regulator in a new BR signal pathway during growth and development.

\section{MATERIALS AND METHODS}

\section{Suspension culture and plant growth}

Seeds of Arabidopsis thaliana BR-deficient mutant det2[35] and BR-insensitive mutant bri1-1[6] were surface sterilized and cultured on B5 medium containing $2 \%$ glucose, $4.5 \mu M 2$,4-dichlorophenoxyacetic acid (2,4-D) and $0.45 \mu M$ kinetin (KT) in darkness at $25^{\circ} \mathrm{C}$ for callus induction. The suspension cultures were established and propagated under conditions described previously[16].

The wild-type Arabidopsis (Col-0 ecotype) was used for analysis and transformation. Plants were grown basically on vermiculite saturated with $0.3 \times \mathrm{B} 5$ medium under continuous illumination (80$120 \mu \mathrm{Em}^{-2} \mathrm{sec}^{-2}$ ) at $23^{\circ} \mathrm{C}[36]$.

\section{Plant hormone and inhibitor treatment}

The hormone-starved cells were treated with 24-epibrassinolide (epiBL), 2,4-D, Zeatin (ZT) and/or inhibitors as previously described [16]. The 30-day-old plants of wild-type Col-0 were sprayed with 1 $\mu M$ epiBL to examine the response.

\section{RNA and DNA gel blot analysis}

Total RNA was isolated with guanadine thiocyanate buffer[37]. RNA gel blot analysis was performed according to procedures described previously[16]. Probes were prepared with full-length $R A V 1$ cDNA using a random labeling system (Amersham, UK). The antiRAV1 RNA probe was synthesized by T7 RNA polymerase and used for expression analysis of $R A V 1$ in transgenic plants.

The genomic DNA was prepared from 30-day-old plants by CTAB method[38] and completely digested with appropriate enzymes. The DNA was separated on a $0.8 \%$ agarose gel, transferred onto a nylon filter (Hybond $\mathrm{N}^{+}$, Amersham) and probed with $R A V 1$.

\section{Western blot analysis}

A Sac I and Dra I fragment of RAVI cDNA $(\sim 1.1 \mathrm{~kb})$ without start codon was cloned into the expression vector pGEX-3X (Pharmacia) digested with $S m a I$ and introduced into $E$. coli by electroporation to generate the GST-RAV1 fusion protein. The expression of fusion protein, antibody preparation and immunological detection were conducted according to the methods described previously[39]. Proteins were extracted from det 2 cells treated with/without epiBL as described by Fawcett et al[40].

\section{Sense- and antisense- $R A V 1$ plasmid construction and plant transformation}

To generate two orientation insertions of RAVI cDNA, an $11 \mathrm{bp}$ multiple clone sites containing a $\mathrm{Kp} n \mathrm{I}$ site from pUC118 vector was introduced into pBI121 to form pJL700. An XhoI fragment of fulllength $R A V 1$ cDNA $(1.23 \mathrm{~kb})$ was cloned into pBluescript II SK (+) to generate two plasmids with both trans- and reverse-orientated insertions. The $K p n I$ and $X b a \mathrm{I}$ fragments from both plasmids were ligated to $\mathrm{pJL} 700$ to generate sense- and antisense- $R A V 1$ plasmids, pJL781 and pJL782, respectively. Both pJL781 and pJL782 were introduced into Agrobacterium strain GV3101 by electroporation and were used to transform wild-type Col-0 plants by vacuum infiltration[41]. The transformants were selected in MS medium containing $50 \mathrm{mgL}^{-1}$ kanamycin. The transgenic plants were self-pollinated to generate homozygous transgenic lines and confirmed by DNA gel blot analysis with a CaMV $35 \mathrm{~S}$ promoter probe. Two independent T4 homozygous lines of each construct were used for molecular and phenotypic characterization.

For morphological observation of seedlings, seeds of RAVI transgenic lines and wild-type Col- 0 were germinated in MS plates containing $2 \%$ sucrose and grown vertically in a chamber at $23{ }^{\circ} \mathrm{C}$ with $16 \mathrm{~h}$ light/ $8 \mathrm{~h}$ dark photoperiod. The lateral root number was counted under microscope.

\section{RESULTS}

\section{$R A V 1$ is down-regulated by epibrassinolide}

To identify BR response genes $(B R R)$, we used cDNA array to monitor gene expression of Arabidopsis det 2 suspension cultures treated with 24-epibrassinolide (epiBL). In a total of 13,000 arrayed cDNA clones, 53 (desig-nated as $B R R 1-B R R 53$ ) were found to be BR responsive[22]. Sequencing and homology analyses showed that the $B R R 8$, a BR down-regulated clone with a $1.23 \mathrm{~kb}$ cDNA, is identical to RAV1 gene (EMBL GenBank accession No. AB013886, At1g13260).

To confirm and further understand the regulation of $R A V 1$ by BR, RNA gel blot analyses of det 2 cells and wild type Col-0 seedlings were performed. When $\operatorname{det} 2$ cells were treated with different concentrations of epiBL, RAV1 mRNA decreased in a dose-dependent manner and over $1 \mu M$ epiBL effectively repressed $R A V 1$ transcription (Fig 1A). Kinetics study showed that the most dramatic re- 


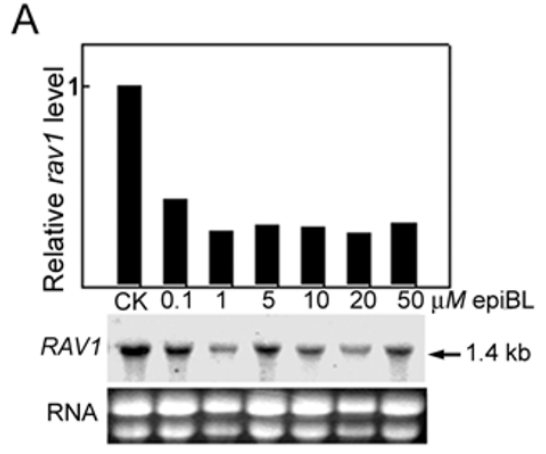

B

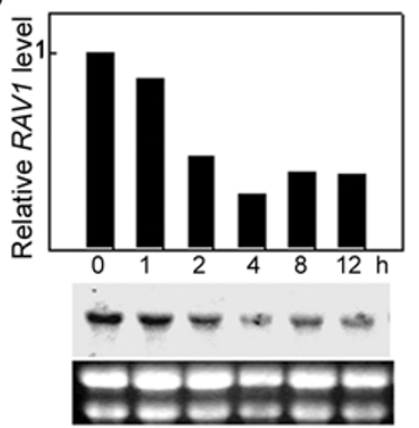

C

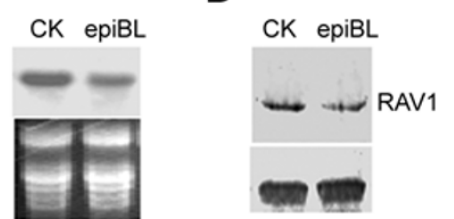

Fig 1. Down-regulation of $R A V 1$ by epibrassinolide. (A-C)The transcriptional repression of $R A V I$ by epibrassinolide (epiBL). All data shown were calibrated against the RNA loadings. (A) The det 2 cells were treated with different concentrations of epiBL or DMSO (CK) for $4 \mathrm{~h}$. (B) The $\operatorname{det} 2$ cells were incubated in the medium supplemented with $5 \mu M$ epiBL for various times after hormone starvation. (C) 30-day-old plants of wild-type Col-0 were sprayed with $1 \mu M$ epiBL or equal concentration of DMSO (CK) and harvested after 24 h. (D) Western blot analysis of RAV1 in the epiBL-treated det 2 cells. Proteins were isolated from det 2 cells treated with $5 \mu M$ epiBL or equal volume of DMSO (CK) for $4 \mathrm{~h}$ and RAV1 was determined by the affinity with purified anti-GST-RAV1 antibody. The lower non-specific bind served as the loading control.

pression occurred when $\operatorname{det} 2$ cells were incubated for $4 \mathrm{~h}$ with $5 \mu M$ epiBL (Fig 1B). We further investigated this down-regulation in the wild-type plant. As shown in Fig 1C, 30-day-old seedlings of wild-type plants showed an apparent decrease in $R A V 1 \mathrm{mRNA}$ level at $24 \mathrm{~h}$ after treatment of $1 \mu M$ epiBL. Western blot analysis in the $\operatorname{det} 2$ cells showed that incubation with $5 \mu \mathrm{M}$ epiBL for $4 \mathrm{~h}$ caused about 50\% decrease of RAV1 level (Fig 1D). These results indicate that RAV1 is down-regulated by BR.

Responses of $R A V 1$ to other hormones essential for

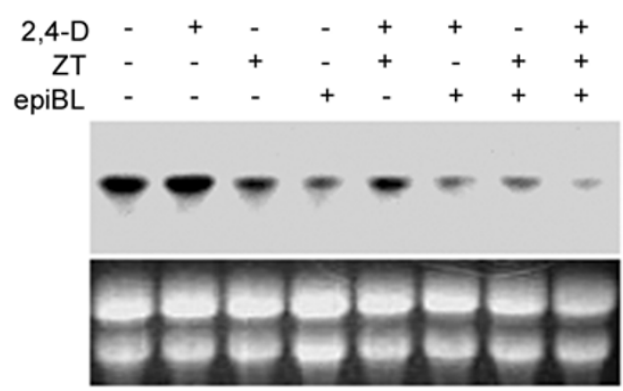

Fig 2. The effect of auxin and cytokinin on RAV1 expression. The RNA was isolated from det 2 cells treated for $4 \mathrm{~h}$ with 2,4-D (4.5 $\mu \mathrm{M})$, ZT $(1 \mu M)$, epiBL $(5 \mu M)$ and their combinations indicated or equal volume of DMSO (CK).

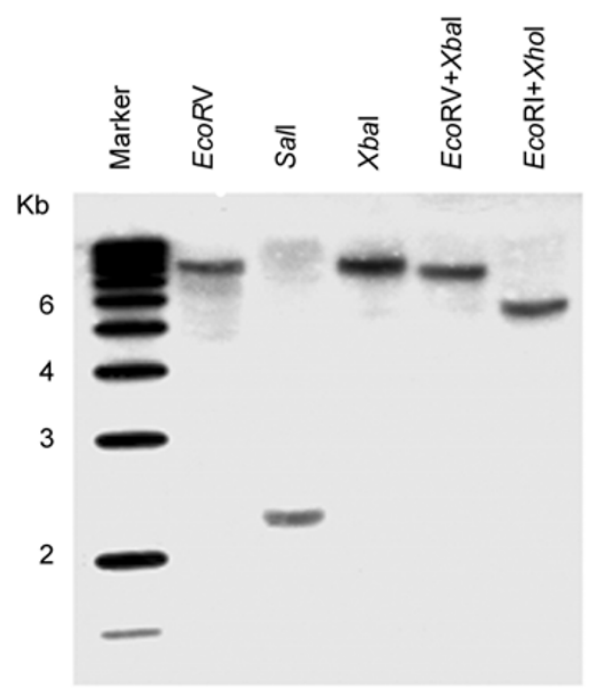

Fig 3. DNA gel blot analysis of RAV1 gene in the Arabidopsis genome. Wild-type Col-0 genomic DNA was digested with the enzymes indicated and transferred onto a nylon filter. The filter was probed with $R A V 1$ fragment and the probed DNA marker was shown at left.

plant growth and development were also examined. As shown in Fig 2, no obvious alteration of RAV1 expression was found in cells treated with 2,4-D. However, a slight repression of $R A V 1$ transcription by zeatin was observed and zeatin showed some synergistic effect with epiBL. These results indicate that $R A V 1$ is mainly responsive to $\mathrm{BR}$, and also to a less extent to cytokinin.

\section{$R A V 1$ is a single copy gene}

The putative amino acid sequence of RAV 1 contains two different DNA binding domains, an AP2 near N-terminal and a B3 in C-terminal[25]. Blast analysis showed that in the Arabidopsis genome there are 5 other putative genes that encode both B3 and AP2 domains (At3g25730, At1g68840, At1g25560, At1g50680 and Atlg51120) with 
A

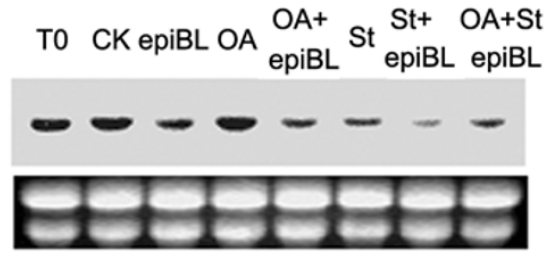

B

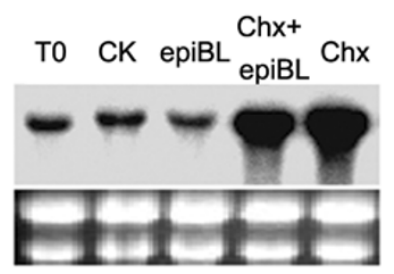

C

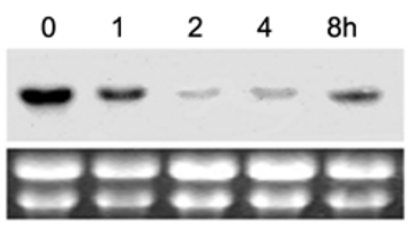

Fig 4. Pathway analysis of epiBL-regulated $R A V 1$ transcription. (A) Protein phosphatase inhibitor okadaic acid (OA) and kinase inhibitor staurosporine (St) showed no effect on the repression by epiBL. The RNA was extracted from det 2 cells incubated for $4 \mathrm{~h}$ with DMSO (CK), epiBL $(5 \mathrm{~m} M)$, OA $(0.1 \mathrm{~m} M)$, St $(1 \mathrm{~m} M)$ and their combinations as indicated. (B) Protein synthesis inhibitor cycloheximide (Chx) greatly induced RAVI but showed no obvious effect on the down-regulation by epiBL. The RNA was prepared from $\operatorname{det} 2$ cells pretreated with ethanol (CK and epiBL) or $100 \mathrm{~m} M \mathrm{Chx}$ for $1 \mathrm{~h}$ and then for additional $4 \mathrm{~h}$ with $5 \mathrm{mM}$ epiBL (Chx+epiBL) or with equal volume DMSO (CK and Chx). (C) Transcritional down-regulation of RAVI by epiBL in bril-1 mutant cells. The RNA was from bril cells treated with $5 \mathrm{mM}$ epiBL for $0,1,2$ and $4 \mathrm{~h}$ after hormone starvation.

41.4-67.7\% identity to $R A V 1$, suggesting that $R A V 1$ belongs to a small novel gene family. However, DNA gel blot analysis under high stringency with full-length $R A V I \mathrm{cDNA}$ probe demonstrated that $R A V 1$ is a single copy gene in Arabidopsis genome (Fig 3).

\section{Transcriptional regulation of $R A V 1$ by epi-brassin- olide does not require the function of BRI1}

To investigate the pathway leading to down-regulation of $R A V 1$ transcription by $\mathrm{BR}$, we examined $R A V 1$ expression in $\operatorname{det} 2$ cells treated with inhibitors widely used in signal transduction research. Okadaic acid (OA), a phosphatase inhibitor, showed no effects on $R A V 1$ repression by epiBL, nor did the strauroprine (St), a broad range inhibitor of protein kinase (Fig 4A), suggesting that protein phosphorylation or dephosphorylation is unlikely involved in the pathway leading to BR-regulated $R A V 1$ transcription. Interestingly, the presence of protein synthesis inhibitor

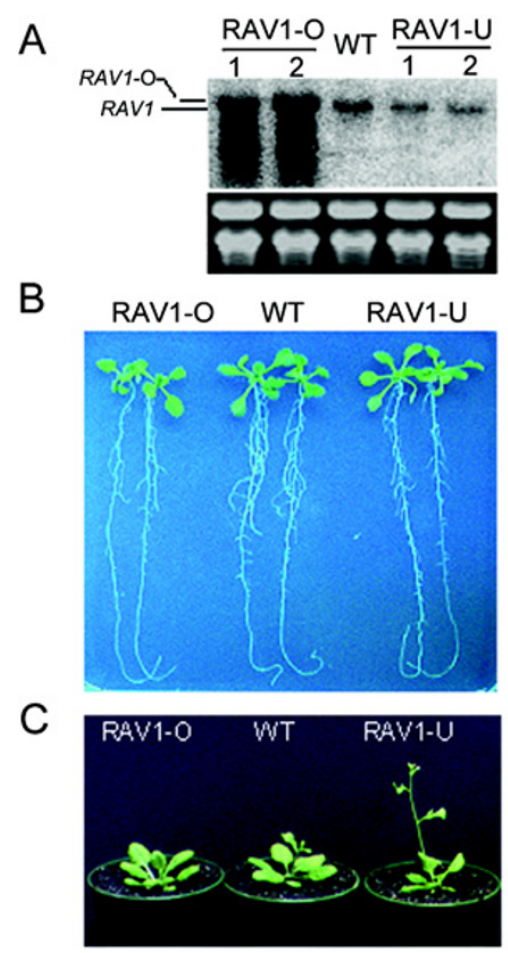

Fig 5. Molecular and morphological characterization of $R A V 1$ transgenic plants. (A) RAVI expression analysis with 20-day-old plants of wild-type Col-0 (WT), 2 independent $R A V 1$ overexpression (RAV1-O) and underexpression (RAV1-U) lines. Blot was probed with the anti-RAV1 RNA probe. (B) The phenotype of lateral roots and rosettes of WT and $R A V 1$ transgenic seedlings. Seedlings were grown vertically on MS medium at $23^{\circ} \mathrm{C}$ for 14 days. (C) The 30 day-old plants of wild-type and $R A V 1$ transgenic plants.

cyclohexmide (Chx) dramatically induced $R A V l$ expression (Fig 4B), suggesting that a short-lived repressor is involved in RAV1 transcriptional control. However, the repression by epiBL was also observed even in the presence of Chx (Fig 4B), implicating that the newly synthesized protein is not essential for BR-regulated RAVI transcription.

Similar to our previous observation in $C y c D 3$ induction by epiBL[16], it seems that BRI1 is not essential for BRregulated $R A V 1$ expression. To test this hypothesis, an RNA gel blot analysis was carried out in the suspension culture of bri1-1, a BR-insensitive mutant in which BRI1 pathway is blocked[6]. When bril-1 cells were treated with $5 \mu \mathrm{M}$ epiBL, RAV1 transcripts decreased considerably (Fig 4C) to a level even lower than that in $\operatorname{det} 2$ cells (Fig 1B). These results imply that regulation of RAVI by $\mathrm{BR}$ does not require functional BRI1. 
Tab 1. Lateral root, rosette leaf number and flowering time of wild-type and $R A V 1$ transgenic plants

\begin{tabular}{lccc}
\hline Type of plant ${ }^{\mathrm{a}}$ & $\begin{array}{c}\text { Lateral root } \\
\text { number }^{\mathrm{b}}\end{array}$ & $\begin{array}{c}\text { Rosette leaf } \\
\text { number }^{\mathrm{b}}\end{array}$ & $\begin{array}{c}\text { Flowering time } \\
(\text { day })\end{array}$ \\
\hline RAV1-O & $25.2 \pm 3.45^{\mathrm{c}}$ & $6.06 \pm 0.71^{\mathrm{d}}$ & $34.2 \pm 1.15$ \\
Wildtype & $35.2 \pm 4.01$ & $7.45 \pm 0.52$ & $32.4 \pm 1.27$ \\
RAV1-U & $34.7 \pm 4.65$ & $7.63 \pm 0.58$ & $27.6 \pm 2.24^{\mathrm{c}}$ \\
\hline
\end{tabular}

a Data represent the average and standard error of at least 30 plants in wid-type and two independent lines of both RAV1-O and RAV1-U. ${ }^{b}$ The number of lateral roots and rosette leaves was counted with 14-day-old seedlings grown vertically on MS medium.

${ }^{c}$ The $99 \%$ confidence intervals.

${ }^{\mathrm{d}}$ The $95 \%$ confidence intervals

\section{Alteration of RAV1 expression affects lateral root and rosette leaf development and flowering time}

To understand the role of RAV1 in plants, sense and antisense RNA constructs with full-length RAV1 cDNA $(1.23 \mathrm{~kb})$ driven by cauliflower mosaic virus $35 \mathrm{~S}$ promoter were introduced into wild-type plants by Agrobacterium-mediated transformation. 112 and $78 \mathrm{~T} 1$ plants of overexpressing (RAV1-O) and underexpressing (RAV1-U) $R A V 1$ were obtained by kanamycin selection, respectively. After co-segregation and DNA gel blot analysis, two independent T4 homozygous lines in each construct were selected for further characterization. RNA gel blot analysis with anti-RAV1 probe revealed that compared to wild-type, 20-day-old seedlings of RAV1-U lines showed a relatively lower $R A V 1$ expression, but two RAV1-O lines had much higher levels of $R A V 1$ transcripts (Fig 5A). Surprisingly, an obvious RNA degradation was observed in these two RAV1-O lines (Fig 5A). We then investigated some of other RAV1-O lines and found that the RNA degradation occurred in almost all examined lines (data not shown).

Although RAV1-O and RAV1-U transgenic plants were almost indistinguishable from the wild type after flowering (data not shown), differences could be observed at the early developmental stage. When grown vertically on MS plates, seedlings of RAV1-O lines had apparently less lateral roots and rosette leaves compared to those of wildtype and RAV1-U lines, with decreases of about $30 \%$ and $15 \%$, respectively (Tab 1 and Fig 5B). However, no obvious differences of lateral root and rosette leaf number were found between the wild-type and RAV1-U plants (Tab 1), though the length of lateral roots of RAV1-U seedlings was somewhat shorter than that of the wild-type plants (Fig 5B). These results indicate that overexpression of RAVI has a retardatory effect on development of the lateral root and rosette leaf.
Grown in plates, RAV1-U seedlings exhibited an earlier inflorescence initiation compared to the wild-type and RAV1-O plants. Further examination of these plants in greenhouse indicated that RAV-U plants flowered 4.8 days and 6.6 days earlier than the wild-type and RAV1-O plants, respectively (Tab 1 and Fig 5C). However, the flowering time of RAV1-O plants was delayed 1.8 days compared to that of the wild-type plants, suggesting that underexpression of $R A V 1$ appears to accelerates the development of Arabidopsis seedlings.

\section{DISCUSSION}

\section{$R A V 1$ is a primary $B R$ response gene}

By cDNA array and RNA gel blot analysis, we found that $R A V 1$ is down-regulated by epiBL, indicating that $R A V l$ is a BR response gene. $R A V 1$ mRNA is ubiquitously presented in all Arabidopsis organs, including roots, rosette leaves, cauline leaves, inflorescent stems, flowers, and siliques. The $R A V 1$ expression is relatively high in roots, leaves and stems, but very low in flowers[25]. Our finding that $R A V 1$ is a BR down-regulated gene may partly account for the different expression levels in various organs. For example, a high level of BR in flower is accompanied by a very low level of $R A V 1$ transcripts, and a low level of BR in roots, stems and leaves by a higher expression of $R A V 1$. Therefore, the $R A V 1$ expression and $\mathrm{BR}$ distribution in plants are consistent with the finding that $R A V 1$ is a BR down-regulated gene.

Protein synthesis inhibitor Chx can greatly induce the transcription of most early auxin response genes, $A U X /$ $I A A$ [42]. The dramatic induction of RAVI by Chx suggests that there is a repressor involved in $R A V 1$ transcriptional regulation. However, the observation of down-regulation by epiBL under Chx condition implicates that the newly synthesized protein may not be essential for BRregulated $R A V 1$ expression or the protein required may have already existed in plant cells. Furthermore, the regulation of $R A V 1$ by epiBL occurrs within $1 \mathrm{~h}$ and the protein phosphorylation or dephosphorylation is not involved in this process. All these data demonstrate that $R A V 1$ is a $\mathrm{BR}$ primary response gene.

\section{RAV1 may function as a negative growth regulatory component}

In plant, B3/VP1 domain was mainly found in some $\mathrm{ABA}$ and auxin response factors[32,34] and a large number of AP2-containing proteins were identified to be the regulatory factors in various developmental aspects and responses[28, 29]. The finding that RAV1 contains two unrelated DNA binding domains that bind to two bipartite unrelated sequence motifs separated by various spacing in 
two different orientations[25] suggests that RAV1 may play a regulatory role in some developmental and/or responsive process in plants. The down-regulation of $R A V 1$ by epiBL indicates that RAV1 is involved in BR-regulated development. The observations that the overexpression of RAVI leads to the retarded lateral root and rosette leaf development and the underexpression causes early flowering, along with the finding of the transcriptional repression by cytokinin and RNA degradation in RAV1 overexpressed plants, suggest that RAV1 functions as a negative growth regulatory factor.

In contrast to some morphological alterations before flowering, the $R A V 1$ transgenic plants were almost indistinguishable from the wild-type in later development stage. This might be partly due to the RNA degradation occurred in $R A V 1$ overexpression lines and may explain why Kagaya et al failed to find apparently morphological changes in overexpressed $R A V 1$ plants[25]. According to our results, it is likely that $R A V 1$ only affects the rate of development. Furthermore, the presence of two types of important DNA binding domains confers the possibility that RAV1 might also be involved in some other unidentified responses in plants. Therefore, further work is needed in searching of RAV1 target genes to understand the regulatory mechanism.

\section{BR may regulate RAV1 through a BRI1-independent signal pathway}

Our observation that the epiBL-regulated $R A V 1$ expression involves neither protein phosphorylation/dephosphorylation nor protein synthesis and occurs in the bril mutant cells suggests that BR regulates $R A V 1$ transcription through a pathway other than the BRI1, a pathway identified and well-characterized so far to perceive and transduce BR signals[3]. Our previous analysis of BR-induced $C y c D 3$ expression has suggested that apart from BRI1, there may exist an unidentified BR signal pathway through which BR induces $C y c D 3$ transcription and promotes cell division[16]. Recently, an antisense inhibition of BRI1 receptor in rice also revealed that an additional protein kinase signaling component may function downstream to the perception of BR[43].

In animals, there coexist two pathways to transduce steroid hormone signals. The first involves a membranelocated receptor with an extracellular ligand domain to perceive hormone signals, and an intracellular domain responsible for transducing signal through a protein phosphorylation cascade to mediate some responses[44]. The second pathway involves an intracellular steroid-activated receptor complex to directly regulate the transcription of genes by binding to the promoter[45]. In plants, although a chaperon heterocomplex similar to that of intracellular steroid receptor in animal has been identified[46-48], nei-

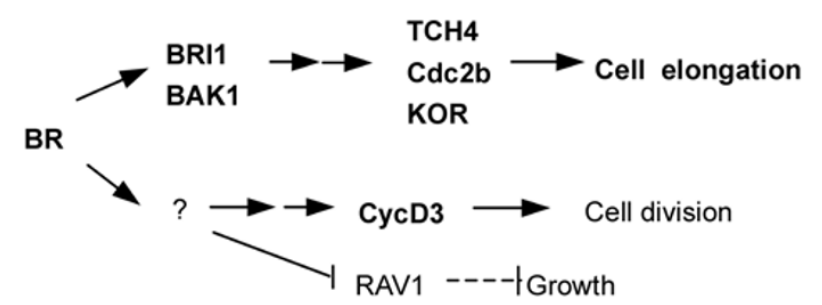

Fig 6. A model for BR signal transduction. BRI1, a membranelocated BR receptor, interacts with BAK1 and perceives BR signal and transduces it through a cascade of protein phosphorylation and dephosphorylation, causes the non-genomic effect and transcriptional regulation of some BR response genes such as $T C H 4, C d c 2 b$ and $K O R$, and then affects cell elongation and some responses. Paralle to BRI1, BR might interact with an unknown receptor or component to regulate expression of some other BR response genes such as $C y c D 3$ and $R A V 1$, resulting in the promotion of cell division and other subsequent physiological responses in plants.

ther the candidate gene encoding a putative intracellular receptor of BR has been found in the Arabidopsis genome [49], nor evidence suggested the existence of BR intracellular receptor. However, three BRI1 homologue were identified in Arabidopsis genome[49]. Therefore, it is possible that BR-regulated transcription of $C y c D 3$ and $R A V 1$ is through another BRI1 homologues or plant might have an unrelated class of steroid receptors whose identity has not been discovered yet (Fig 6)[50].

\section{ACKNOWLEDGMENT}

This work was supported by grants from the National Natural Science Foundation of China (No. 39889003, 30070074, 30221002) and a National Distinguished Young Scholar Award to Jia Yang LI.

Received, Sep 8, 2003

Revised, Oct 30, 2003

Accepted, Nov 6, 2003

\section{REFERENCES}

1 Mandava NB. Plant growth-promoting brassinosteroids. Annu Rev Plant Physiol Plant Mol Biol 1988; 39:23-52.

2 Clouse SD, Sasse JM. Brassinosteroids: essential regulators of plant growth and development. Annu Rev Plant Physiol Plant Mol Biol 1998; 49:427-51.

3 Schumacher K, Chory J. Brassinosteroid signal transduction: still casting the actors. Curr Opin Plant Biol 2000; 3:79-84.

4 Altmann T. Recent advances in brassinosteroid molecular genetics. Curr Opin Plant Biol 1998; 1:378-83.

5 Clouse SD, Langford M, McMorris TC. A brassinosteroid-insensitive mutant in Arabidopsis thaliana exhibits multiple defects in growth and development. Plant Physiol 1996; 111:671-8.

6. Li J, Chory J. A putative leucine-rich repeat receptor kinase involved in brassinosteroid signal transduction. Cell 1997; 90: 
929-38.

7. He Z, Wang ZY, Li J, Zhu Q, Lamb C, Ronald P, Chory J. Perception of brassinosteroids by the extracellular domain of the receptor kinase BRI1. Science 2000; 288:2360-3.

8 Wang ZY, Seto H, Fujioka S, Yoshida S, Chory J. BRI1 is a critical component of a plasma-membrane receptor for plant steroids. Nature 2001; 410:380-3.

9 Li J, Lease KA, Tax FE, Walker JC. BRS1, a serine carboxypeptidase, regulates BRI1 signaling in Arabidopsis thaliana. Proc Natl Acad Sci USA 2001; 98:5916-21.

10 Li J, Nam KH, Vafeados D, Chory J. BIN2, a new brassinosteroidinsensitive locus in Arabidopsis. Plant Physiol 2001; 127:14-22.

11 Li J, Wen J, Lease KA, Doke JT, Tax FE, Walker JC. BAK1, an Arabidopsis LRR receptor-like protein kinase, interacts with BRI1 and modulates brassinosteroid signaling. Cell 2002; 110: 213-22.

12 Li J, Nam KH. Regulation of brassinosteroid signaling by a GSK3/ SHAGGY-like kinase. Science 2002; 295:1299-301.

13 Nam KH, Li J. BRI1/BAK1, a receptor kinase pair mediating brassinosteroid signaling. Cell 2002; 110:203-12.

14 Zurek DM, Clouse SD. Molecular cloning and characterization of a brassinosteroid-regulated gene from elongating soybean (Glycine max L.) epicotyls. Plant Physiol 1994; 104:161-70.

$15 \mathrm{Xu}$ W, Purugganan MM, Polisenksy DH, Antosiewicz DM, Fry SC. Arabidopsis TCH4 regulated by hormones and environment, encodes a xyloglucan endotransglycosylase. Plant Cell 1995; 7:1555-67.

$16 \mathrm{Hu} \mathrm{Y,} \mathrm{Bao} \mathrm{F,} \mathrm{Li} \mathrm{J.} \mathrm{Promotive} \mathrm{effect} \mathrm{of} \mathrm{brassinosteroids} \mathrm{on} \mathrm{cell}$ division involves a distinct $C y c D 3$-induction pathway. Plant $\mathbf{J}$ 2000; 24:693-701.

17 Li J, Nagpal P, Vitart V, McMorris TC, Chory J. A role for brassinosteroids in light-dependent development of Arabidopsis. Science 1996; 272:398-401.

18 Kang JG, Yun J, Kim DH et al. Light and brassinosteroid signals are integrated via a dark-induced small $\mathrm{G}$ protein in etiolated seedling growth. Cell 2001; 105:625-36.

19 Yoshizumi T, Nagata N, Shimada H, Matsui M. An Arabidopsis cell cycle-dependent kinase-related gene, $C D C 2 b$, plays a role in regulating seedling growth in darkness. Plant Cell 1999; 11:188396.

20 Nicol F, His I, Jauneau A, Vernhettes S, Canut H, Hofte H. A plasma membrane-bound putative endo-1,4-beta-D-glucanase is required for normal assembly and cell elongation in Arabidopsis. EMBO J 1998; 17:5563-76.

21 Neff MM, Nguyen SM, Malancharuvil EJ et al. BAS1: A gene regulating brassinosteroid levels and light responsiveness in Arabidopsis. Proc Natl Acad Sci USA 1999; 96:15316-23.

$22 \mathrm{Hu}$ Y, Wang Z, Wang Y, Bao F, Li N, Peng Z, Li J. Identification of brassinosteroid responsive genes in Arabidopsis. Sci China (Seri C) 2001; 44:637-43.

23 Goda H, Shimada Y, Asami T, Fujioka S, Yoshida S. Microarray analysis of brassinosteroid-regulated genes in Arabidopsis. Plant Physiol 2002; 130:1319-34.

24 Mussig C, Fischer S, Altmann T. Brassinosteroid-regulated gene expression. Plant Physiol 2002; 129:1241-51.

25 Kagaya Y, Ohmiya K, Hattori T. RAV1, a novel DNA-binding protein, binds to bipartite recognition sequence through two distinct DNA-binding domains uniquely found in higher plant. Nucleic Acids Res 1999; 27:470-8.
26 Ohme-Takagi M, Shinshi H. Ethylene-inducible DNA binding prteins that interact with an ethylene-responsive elements. Plant Cell 1995; 7:173-82.

27 Jofuku KD, den Boer BGW, Van Montagu M, Okamuro JK. Control of Arabidopsis flower and seed development by the homeotic gene APETALA2. Plant Cell 1994; 6:1211-25.

28 Weigel D. The APETALA2 domain is related to a novel type of DNA binding protein. Plant Cell 1995; 7:388-9.

29 Sakuma Y, Liu Q, Dubouzet JG, Abe H, Shinozaki K, YamaguchiShinozaki K. DNA-binding specificity of the ERF/AP2 domain of Arabidopsis DREBs, transcription factors involved in dehydration- and cold-inducible gene expression. Biochem Biophys Res Commun 2002; 290:998-1009.

30 Wilson K, Long D, Swinburne J, Coupland G. A dissociation insertion causes a semidominant mutation that increases expression of TINY, an Arabidopsis gene related to APETALA2. Plant Cell 1996; 8:659-71.

31 Jaglo-Ottosen KR, Gilmour SJ, Zarka DJ, Schabenberger O, Thomashow MF. Arabidopsis $C B F 1$ overexpression induces COR genes and enhance freezing tolerance. Science 1998; 280: 104-6.

32 Giraudat J, Hauge BM, Valon C, Smalle J, Parcy F,Goodman HM. Isolation of the Arabidopsis ABI3 gene by positional cloning. Plant Cell 1992; 4:1251-61.

33 McCarty DR, Hattori T, Carson CB, Vasil V, Lazar M, Vasil IK. The Viviparous-1 developmental gene of maize encodes a novel transcriptional activator. Cell 1991; 66:895-905.

34 Ulmasov T, Hagen G, Gulfoyle TJ. ARF1, a transcription factor that binds to auxin response elements. Science 1997; 276:18658.

35 Fujioka S, Li J, Choi YH et al. The Arabidopsis deetiolated2 mutant is blocked early in brassinosteroid biosynthesis. Plant Cell 1997; 9:1951-62.

36 Mou Z, He Y, Dai Y, Liu X, Li J. Deficiency in fatty acid synthase leads to premature cell death and dramatic alterations in plant morphology. Plant Cell 2000; 12:404-17.

37 Wadsworth GJ, Redinbaugh MG, Scandalios JG. A procedure for small-scale isolation of plant RNA suitable for RNA blot analysis. Anal Biochem 1988; 172:279-83.

38 Li J, Zhao J, Rose AB, Last LR. Arabidopsis phosphoribsylanthranilate isomerase: molecular genetic analysis of triplicate tryptophan pathway genes. Plant Cell 1995; 7:447-61.

39 Liu X, Ouyang J, He Y, Li J. Immunological analysis of Arabidopsis indole-3-glycerol phosphate synthase. Acta Bot Sinica 1999; 41:751-6.

40 Fawcett T, Simon WJ, Swinhoe R, Shanklin J, Nishida I, Christie WW, Slabas AR. Expression of mRNA and steady-state levels of protein isoforms of enoyl-ACP reductase from Brassica napus. Plant Mol Biol 1994; 26:155-63.

41 Bechtold N, Ellis J, Pelletier G. In planta Agrobacterium mediated gene transfer by infiltration of adult Arabidopsis thaliana plants. C R Acad Sci Paris, Sciences de la vie/Life Sciences 1993; 316: 1194-9.

42 Abel S, Theologis A. Early genes and auxin action. Plant Physiol 1996; 111:9-17.

43 Sharma A, Matsuoka M, Tanaka H, Komatsu S. Antisense inhibition of a BRI1 receptor reveals additional protein kinase signaling components downstream to the perception of brassinosteroids in rice. FEBS Lett 2001; 507:346-50. 
44 Mendona C, Soler A, Tesarik J. Nongenomic steroid action: independent targeting of a plasma membrane calcium channel and a tyrosine kinase. Biochem Biophys Res Comm 1995; 210:518-23.

45 Beato M, Herrlich P, Schytz G. Steroid hormone receptors: many actors in search of a plot. Cell 1995; 83:153-6.

46 Owens-Grillo JK, Stancato LF, Hoffmann K, Pratt WB, Krishna P. Binding of immunophilins to the $90 \mathrm{kDa}$ heat shock protein (hsp90) via a tetratricopeptide repeat domain is a conserved protein interaction in plant. Biochemistry 1996; 25:15249-55.

47 Reddy RK, Kurek I, Silverstein AM, Chinkers M, Breiman A, Krishna P. High-molecular-weight FK506-binding proteins are components of heat-shock protein 90 heterocomplex in wheat germ lysate. Plant Physiol 1998; 118:1395-401.

48 Stancato LF, Hutchison KA, Krishna P, Pratt WB. Animal and plant cell lysates share a conserved chaperone system that assembles the glucocorticoid receptor into a functoinal heterocomplex with hsp90. Biochemistry 1996; 35:554-61.

49 Arabidopsis Genome Initiative. Analysis of the genome sequence of the flowering plant Arabidopsis thaliana. Nature 2000; 408: 796-815.

50 Friedrichsen D, Chory J. Steroid signaling in plants: from the cell surface to the nucleus. Bioessays 2001; 23:1028-36. 